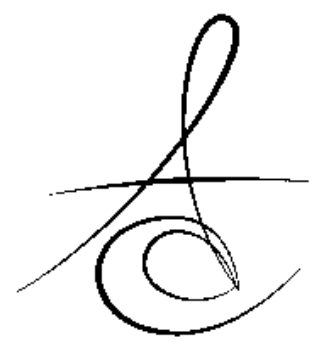

\title{
KRONİK PERİODONTİTİSLİ HASTALARDA KEMİKİÇİ DEFEKTLERİN DAĞILIMLARININ İNCELENMESİ
}

\author{
THE INVESTIGATION OF THE DISTRIBUTION OF INFRABONY DEFECTS IN \\ CHRONIC PERIODONTITIS PATIENTS
}

\author{
Dr. Pelin GÖKALP*
}

\author{
Arş. Gör. Dr. Zeynep TURGUT ÇANKAYA**
}

Makale Kodu/Article code: 2193

Makale Gönderilme tarihi: 10.03.2015

Kabul Tarihi: 13.04.2015

\section{ÖZET}

Amaç: $\mathrm{Bu}$ çalışmanın amacı, kronik periodontitisli hastalarda periodontal cerrahi operasyonlar sırasında gözlenen kemikiçi defektlerin dağılımlarını incelemektir.

Materyal Metod: Klinik ve radyografik muayene sonrası kronik periodontitisli 47 hasta çalışmaya dahil edilmiştir. Tam kalınlık mukoperiostal flepler kaldırılıktan sonra kemik defektleri 1,2,3 duvarlı ve kombine defekt olarak sınıflandırılarak, kaydedilmiştir. 97' si maksillada, 88 'i mandibulada toplam 185 adet kemik defekti saptanmıştır.

Bulgular: Maksilla ve mandibula arasında 1 duvarlı, 2 duvarlı ve kombine kemik defektlerinde istatistiksel olarak anlamlı bir farklılık görülmemekle birlikte 3 duvarlı kemik defektlerinde istatistiksel olarak farklılık bulunmuştur. 1, 2 duvarlı ve kombine kemik defektleri posterior bölgede anterior bölgeye göre daha fazla sayıda görülmüştür. İncelenen tüm defektlerin \% 50.2 'sini 2 duvarlı defekti oluşturmaktadır.

Sonuç: Çalışmamızda; maksilla, mandibula ve anterior, posterior bölgeler arasındaki anatomik farklılıklar ve alveolar kemiğin morfolojisine bağlı olarak kemik defektlerinin dağılımlarının değiştiği gözlenmektedir.

Anahtar kelimeler: Kronik periodontitis, kemikiçi defektler, dağılım, periodontal cerrahi

\section{ABSTRACT}

Aim: The purpose of the present investigation was to evaluate the distribution of infrabony defects using direct observation during periodontal surgery in chronic periodontitis patients.

Material Method: After clinical and radiograp- hical examination 47 patients with chronic periodontitis included in the study. After full thickness mucoperiosteal flaps were raised, and osseous defect were explored and classified according to their morphology as infrabony defects with $1,2,3$ or combined osseous walls. 185 defects were defected, 97 were in maxilla, 88 were in the mandible.

Results: The comparison between maxilla and mandible showed a significant difference for the infrabony defects with 3 osseous walls but no difference for the infrabony defects with 1,2 and combined osseous walls. Infrabony defects with 1,2 and combined osseous walls were statistically more prevalent in the posterior region than the anterior region. Intrabony defects with 2 osseous walls accounted for $50.2 \%$ of the all defects.

Conclusion: Anatomical variations and the morphology of alveolar bone between maxilla and mandible and the posterior and anterior regions might have been the reason for differences observed.

Key words: Chronic periodontitis, infrabony defects, distribution, periodontal surgery

farklı zamanlarda değişiklik göstermektedir ${ }^{1}$. Periodontal hastalığın aktif olarak tespit edildiği bölgelerde plak birikiminin fazla olduğu ve biriken plağın uzaklaştırılmasının zor olduğu çalışmalar ile gösterilmiştir ${ }^{2}$. Konakçı savunma faktörlerinin etkinliği de, hastalığın olan genellikle ilerleyen, yıkıcı, iltihabi bir hastalık olarak tanımlanan periodontitisin şiddeti, kişiden kişiye, aynı kişinin farklı bölgelerinde ve aynı bölgedeki

\footnotetext{
* Sağlık Bakanlığı İstanbul Okmeydanı Ağız ve Diş Sağığı Hastanesi, Periodontoloji
}

** Gazi Üniversitesi Diş Hekimliği Fakültesi, Periodontoloji AD. 
seyrinde ve şiddetinde ana faktörlerden biridir $^{1,2}$. Bakteri plağı en önemli faktörken; restorasyonlar, dişin anatomik yapısı, çürük ve kök rezorbsiyonları gibi plağın birikmesini kolaylaştıran veya etkisini arttıran değişik lokal faktörler de periodontal hastalık için ikincil olarak rol oynamaktadır. Ayrıca;sistemik faktörler, sigara kullanımı, genetik faktörler, stres ve beslenme alışkanlıkları gibi diğer etkenlerin periodontal hastalığın başlaması ve ilerlemesinde risk faktörü olduğu bilinmektedir ${ }^{3,4,5}$.

Kronik periodontitis klinik olarak dişetinde enflamasyon, cep formasyonu, dişetinde ödem ve renk değişikliği, dişeti kanaması ile karakterizedir ${ }^{1,6,7}$. Çeşitli derinliklerde dişeti cepleri ve hem yatay hem de dikey yönde kemik kaybı gözlenir.

Periodontal tedavinin patojenik mikrofloranın ortadan kaldırıarak periodontal enfeksiyonun engellenmesi ve aktif periodontitis sonucu meydana gelen defektlerin tedavisi olmak üzere iki temel amacı vardır $^{8,9}$. Periodontal kemik defektleri morfolojik ya da gelişimsel anomaliler ve periodontal hastalık sonucu oluşan kemik defektleri olarak iki ana gruba ayrilır ${ }^{10}$. Kemik defektleri tanı, tedavi ve prognozda klinisyenlere yardımcı olmak amacıyla morfolojik ölçütler esas alınarak sınıflandırılmıştır . Periodontal hastalık sonucu alveol kemiğinde çesitli tip ve genişlikte ortaya çıkan kemik defektleri Goldman ve Cohen tarafından 3 ana baslıkta; 1. Kemiküstü defektler 2. Kemikaltı defektler a. Kemikiçi defektler b. Kraterler 3. İnterradiküler defektler (Furkasyon defektleri) şeklinde sınıflandırımışııı ${ }^{11}$.

Klinik olarak periodontal defektlerin teşhisi kli nik ataşman seviyesinin ölçülmesi ve radyografik de ğerlendirme ile o Imaktadır ${ }^{12}$. Radyografik değerlendirmenin superpozisyon ve iki boyutlu görüntülerin yetersiz bilgi verme olasılığı sebebiyle, klinik veriler ile desteklenmesinin gerekliliği bilinmektedir ${ }^{10,12,13}$. Radyografik olarak başlangıç seviyesindeki doku kayı pların saptanması ve radyografilerde kemik ve sert diş yapılarının üstüste çakışmasından dolayı ilerlemiş lezyonların tespiti genellikle oldukça zordur. Klinik ataşman seviyesi ile birlikte radyografik kemik kaybına ilişkin defektin durumu öngörülmekt e iken, defektin esas morfolojisi flep kaldırılığı zaman saptanabil mektedir $^{10,14,15}$. Wouters ve arkadaşlarının radyografik değerlendirmeleri göz önüne alarak yaptıklari çalışmada kemik defekt prevelansı \%32 olarak belirtilirken, sadece posterior dişlerin incelendiği başka bir çalışmada bu oran $\% 13$, diğer bir çalışmada ise $\%$ 10.6 olarak hesaplanmıştı ${ }^{16-18}$.Tal ve arkadaşlarının 81 hastada cerrahi operasyonlar sırasında yaptıkları araştırmada kemik defekti görülme oranı $\% 31.3$ bulunmuştur $^{19}$. Yine Tal ve arkadaşları kuru kafalarda yaptıkları çalışmada kemik defekti oranının \%18 olduğunu söylemiştir ${ }^{20}$. Tal, kuru kafalarda yaptığı çalışmada incelediği kemikiçi defektlerin \% 42' sinin 2 duvarlı defekt olduğunu ve anteriordan posteriora doğru defekt görülme sıklığının arttığını belirtmiştir ${ }^{20}$. Larato, kemikiçi defektlerin en fazla maksiller ve mandibular molar dişlerin mesialinde görüldüğünü söylemiştir ${ }^{21}$. Yapılan başka bir çalışma ise kemik defektlerinin mandibulada posterior bölgede daha fazla oluştuğunu göstermiştir ${ }^{20}$. Periodontal hastalık sonucu oluşan kemik defektelerinin morfolojileri ve lokalizasyonları tedavi planlamasını etkilediği gibi bunlar hakkında bilgi sahibi olmak yapılacak tedavinin başarısını da etkilemektedir.

Çalışmamızda, kronik periodontitisli hastalarda periodontal cerrahi operasyonlar sırasında gözlenen kemikiçi defektlerin dağıımını incelemek amaçlanmıştır.

\section{MATERYAL METOD}

Çalışmaya Gazi Diş Hekimliği Periodontoloji Anabilim Dalı'na periodontal şikayetleri sebebi ile başvuran generalize kronik periodontitisli (KP) 24 erkek, 23 kadın olmak üzere 47 hasta dahil edilmiştir. Hastaların yaş ortalaması 42.6 olarak hesaplanmıştır. Klinik ve radyografik muayene sonrası KP teşhisleri World Workshop 1999 sınılamasına göre yapılmıştır.

Çalışmaya herhangi bir sistemik rahatsızlığı bulunanlar, son 12 ay içinde periodontal tedavi gören bireyler, sigara kullananlar, hamileler, son 3 ay içinde uzun dönemli (2 hafta veya daha fazla) antibiyotik kullananlar dahil edilmemiştir. Çalışmaya dahil edilme kriterleri olarak; 1) generalize kronik periodontitis varlı̆ı, 2) mevcut dişlerin en az 6 tanesinde $4 \mathrm{~mm}$ ve üzeri cep varlığı 3)ağızda en az 20 diş bulunması dikkate alınmışıır.

Oral hijyen eğitimini takiben periodontal el aletleri ve ultrasonik aletlerden yararlanılarak supragingival ve subgingival diştaşı temizliği ve subgingival küretaj ve kök yüzeyi düzeltilmesini içeren periodontal başlangıç tedavileri uygulanmıştır. Cerrahisiz periodontal tedaviden 4 hafta sonra hastalar kontrol için tekrar 
çağırııp ve klinik ölçümler yapılmıştır. Başlangıç tedavisi sonrası dişeti küretajına cevap vermeyen aktif ceplerde kemikiçi defektlerin tedavisi için cerrahi operasyon yapılmasına karar verilmiştir. Bu amaçla ilgili diş bölgelerine lokal anestezi uygulandıktan sonra sulkuler insizyon ile tam kalınlık mukoperiostal flep kaldırılmıştır. İlgili dişlere subgingival küretaj ve kök düzleştirilmesi işlemi yapılarak enflamasyonlu sert ve yumuşak dokular ortamdan uzaklaştırımıştır. Cerrahi operasyon sırasında 185 kemik defekti bölgesi gözlemlenerek şekil ve boyutları belirlenmiştir. Kemik defektleri 1,2,3 duvarlı ve kombine defekt olarak sınıflandırılarak kaydedilmiştir. Kemik defektleri duvar sayılarına göre sınıflandırlırken bulundukları bölgeler alt, üst çene ve anterior, posterior olarak belirtilmiştir. Furkasyon defekti içeren alanlar çalışmadan çıkarılıı̧tır. Kemikiçi defektlerin kalan duvar sayısı ve morfolojilerine göre değerlendirirken şu sınıflandırmadan yararlanılmıștır ${ }^{11}$;

1)Tek duvarlı defekt: genellikle interdental bölgede bulunur ve eğer kalan duvar proksimal duvarsa defekt hemiseptum olarak adlandirılır. Kalan duvar fasiyal veya lingual yüzde de olabilir.

2)2 duvarlı defekt: En sık görülen kemik defektidir. Krater veya interdental krater olarak adlandirılır. 2 duvarlı defekt interdental bölgede bulunur ve fasiyal, lingual kemik duvarlarına sahiptir. Fasiyal ve proksimal (veya lingual ve proksimal ) duvarlar sağlam kaldığında 2 duvarlı defekt oluşur.

3)3 duvarlı defekt: 3 duvarlı kemik içi defekt en sık interdental bölgede görülür. Kalan kemik duvarları fasiyal,lingual ve proksimal kemiktir. Bu tür defektler kemikiçi defekt olarak adlandırıır. 3 duvarlı defekt aynı zamanda fasiyal ve lingual yüzlerde tekne benzeri bir defekt şeklinde ortaya çıkabilir.

4)Kombine defekt: Çanak şeklinde kemik defekti olarak da tanımlanabilir. Kemik cebi, dişi çevreler. Defekt birkaç diş ve birkaç kemik yüzeyi ile sınırıdır. Pek çok kemik lezyonu 1, 2 veya 3 duvarlı kemik defektlerinin bir kombinasyonu şeklinde görülür.

\section{İSTATİSTİKSEL ANALİZ}

Bu çalışmada elde edilen veriler SPSS 20 paket programı aracılığı ile analiz edilmiştir. Verilerin normal dağılım göstermemesi nedeniyle, iki gruplu karşılaştırmalarda Mann-Whitney $U$ testi ve üç ve daha fazla gruplu karşılaştırmalarda ise Kruskall-Wallis $\mathrm{H}$ testi kullanılmıştır. Anlamlıık seviyesi olarak 0,05 kullanılmış olup $p<0,05$ olması durumunda anlamlı farklı̆ı̆ın olduğu, $p>0,05$ olması durumunda ise anlamlı farklıı̆ı̆ın olmadığı belirtilmiştir.

\section{BULGULAR}

Çalışmamızda yeralan 185 adet defekt bölgesi flep operasyonları sırasında gözlemlenerek duvar sayılarına göre 185 defektin 97 tanesi üst çenede, 88 tanesi alt çenede olacak şekilde kaydedilmiştir. Alt ve üst çene arasında 1 duvarlı, 2 duvarlı, 3 duvarlı ve kombine kemik defektlerinde istatistiksel olarak anlamlı bir farklılık görülmemekle birlikte 3 duvarlı kemik defektlerinde alt çenede daha az sayıda kemik defektine rastlanmıştır. (Tablo 1 )

Çalışmamızda kemik defektleri sınıflandırılırken anterior ve posterior olarak hangi bölgede oldukları belirtilmiştir. 31 kemik defekti anterior bölgede ,154 kemik defekti posterior bölgede bulunmaktadır. 1 duvarlı, 2 duvarlı ve kombine kemik defektleri için anterior ve posterior bölgeler arasında istatistiksel olarak anlamlı bir farklılık görülmüştür. Posterior bölgelerde anterior bölgeye göre daha fazla sayıda kemik defektine rastlanmıştır. 3 duvarlı kemik defekti için istatistiksel bir farklılık görülmemiştir. (Tablo 2)

Çalışmamızda ayrıca kemik defektleri anterior üst, posterior üst, antereior alt, posterior alt olarak bölgesel gruplara ayrılarak istatistiki farklar hesaplanmıştır. 1 duvarlı defektler için posterior alt bölgede gözlenen kemik defektleri anlamlı olarak fazla, anterior üst bölgede ise anlamlı olarak daha az bulunmuştur. 2 duvarlı defektler ve kombine defektlerin ise posterior üst ve posterior alt bölgelerde anlamlı olarak daha fazla olduğu görülmüştür. (Tablo 3)

Çalışmamızda, incelenen tüm kemik defektleri içinde en fazla (\% 50,2 oranında) 2 duvarlı kemik defektine rastlanmıştır. Kombine kemik defekleri \% 20, 1 duvarlı kemik defekteri \% 17.8, 3 duvarlı kemik defektleri \% 11.89 oranında gözlenmiştir. 
Tablo 1. Defekt Tiplerine göre Alt Çene ve Üst Çene Arasındaki Dağılımlara İlişkin Farklar

\begin{tabular}{|c|c|c|c|c|c|c|c|c|c|c|}
\hline & & \multirow[b]{2}{*}{$\mathbf{N}$} & \multirow[b]{2}{*}{ Mean } & \multirow[b]{2}{*}{ Median } & \multirow[b]{2}{*}{ Min } & \multirow[b]{2}{*}{ Max } & \multirow[b]{2}{*}{ ss } & \multicolumn{3}{|c|}{ Mann-Whitney U Testi } \\
\hline & & & & & & & & Sıra Ort. & $\mathbf{U}$ & $\mathbf{P}$ \\
\hline \multirow{2}{*}{$\begin{array}{l}1 \text { duvarlı } \\
\text { defekt }\end{array}$} & Üstçene & 14 & 1.07 & 1 & 0 & 3 & 1 & 13.57 & \multirow{2}{*}{85} & \multirow{2}{*}{0.531} \\
\hline & Altçene & 14 & 1.29 & 1 & 0 & 3 & 0.91 & 15.43 & & \\
\hline \multirow{2}{*}{$\begin{array}{l}2 \text { duvarlı } \\
\text { defekt }\end{array}$} & Üstçene & 14 & 3.43 & 3 & 1 & 7 & 2.10 & 14.93 & \multirow{2}{*}{92} & \multirow{2}{*}{0.78} \\
\hline & Altçene & 14 & 3.21 & 3.5 & 0 & 7 & 2.26 & 14.07 & & \\
\hline \multirow{2}{*}{$\begin{array}{l}3 \text { duvarlı } \\
\text { defekt }\end{array}$} & Üstçene & 14 & 1 & 1 & 0 & 3 & 0.68 & 16.93 & \multirow{2}{*}{64} & \multirow{2}{*}{0.081} \\
\hline & Altçene & 14 & 0.57 & 0 & 0 & 2 & 0.76 & 12.07 & & \\
\hline \multirow{2}{*}{$\begin{array}{l}\text { kombine } \\
\text { defekt }\end{array}$} & Üstçene & 14 & 1.43 & 1 & 0 & 5 & 1.45 & 14.75 & \multirow{2}{*}{94,5} & \multirow{2}{*}{0.867} \\
\hline & Altçene & 14 & 1.21 & 1 & 0 & 3 & 1.05 & 14.25 & & \\
\hline
\end{tabular}

Tablo 2. Defekt Tiplerine göre Anterior ve Posterior Bölgeler Arasındaki Dağılımlara İlişkin Farklar

\begin{tabular}{|c|c|c|c|c|c|c|c|c|c|c|}
\hline & & \multirow[b]{2}{*}{$\mathbf{n}$} & \multirow[b]{2}{*}{ Mean } & \multirow[b]{2}{*}{ Median } & \multirow[b]{2}{*}{ Min } & \multirow[b]{2}{*}{ Max } & \multirow[b]{2}{*}{ ss } & \multicolumn{3}{|c|}{ Mann-Whitney U Testi } \\
\hline & & & & & & & & Sıra Ort. & U & $\mathbf{P}$ \\
\hline \multirow{2}{*}{$\begin{array}{l}1 \text { duvarlı } \\
\text { defekt }\end{array}$} & anterior & 12 & 0.33 & 0 & 0 & 1 & 0.49 & 7.33 & \multirow{2}{*}{10} & \multirow{2}{*}{$0.0001 *$} \\
\hline & posterior & 16 & 1.81 & 2 & 1 & 3 & 0.66 & 19.88 & & \\
\hline \multirow{2}{*}{$\begin{array}{l}2 \text { duvarlı } \\
\text { defekt }\end{array}$} & anterior & 12 & 1.33 & 1 & 0 & 3 & 0.98 & 6.92 & \multirow{2}{*}{5} & \multirow{2}{*}{$0.0001 *$} \\
\hline & posterior & 16 & 4.81 & 5 & 2 & 7 & 1.42 & 20.19 & & \\
\hline \multirow{2}{*}{$\begin{array}{l}3 \text { duvarlı } \\
\text { defekt }\end{array}$} & anterior & 12 & 0.58 & 1 & 0 & 1 & 0.51 & 12.79 & \multirow{2}{*}{75.5} & \multirow{2}{*}{0.288} \\
\hline & posterior & 16 & 0.94 & 1 & 0 & 3 & 0.85 & 15.78 & & \\
\hline \multirow{2}{*}{$\begin{array}{l}\text { kombine } \\
\text { defekt }\end{array}$} & anterior & 12 & 0.33 & 0 & 0 & 1 & 0.49 & 7.50 & \multirow{2}{*}{12} & \multirow{2}{*}{$0.0001 *$} \\
\hline & posterior & 16 & 2.06 & 2 & 1 & 5 & 1.12 & 19.75 & & \\
\hline
\end{tabular}

Tablo 3. Defekt Tiplerine Göre Bölgesel Gruplar Arasındaki Dağılımlara İlişkin Farklar

\begin{tabular}{|c|c|c|c|c|c|c|c|c|c|c|c|}
\hline & & \multirow[b]{2}{*}{$\mathbf{n}$} & \multirow[b]{2}{*}{ Mean } & \multirow[b]{2}{*}{ Median } & \multirow[b]{2}{*}{ Min } & \multirow[b]{2}{*}{ Max } & \multirow[b]{2}{*}{ ss } & \multicolumn{3}{|c|}{ Kruskal Wallis Testi } & \multirow{2}{*}{$\begin{array}{l}\text { İkili } \\
\text { Karşılaştırma }\end{array}$} \\
\hline & & & & & & & & Sira Ort. & $\mathbf{H}$ & $\mathbf{P}$ & \\
\hline \multirow{4}{*}{1 duvarlı defekt } & $1=$ anterior üst & 6 & 0.17 & 0 & 0 & 1 & 0.41 & 5.92 & \multirow{4}{*}{17.97} & \multirow{4}{*}{0.0001} & \multirow{4}{*}{$\begin{array}{l}1-2 \\
1-4 \\
3-4\end{array}$} \\
\hline & $2=$ posterior üst & 8 & 1.75 & 2 & 1 & 3 & 0.71 & 19.31 & & & \\
\hline & $3=$ anterior alt & 6 & 0.5 & 0.5 & 0 & 1 & 0.55 & 8.75 & & & \\
\hline & $4=$ posterior alt & 8 & 1.88 & 2 & 1 & 3 & 0.64 & 20.44 & & & \\
\hline \multirow{4}{*}{ 2duvarlı defekt } & $\mathbf{1}=$ anterior üst & 6 & 1.5 & 1 & 1 & 3 & 0.84 & 7.58 & \multirow{4}{*}{18.34} & \multirow{4}{*}{0.0001} & \multirow{4}{*}{$\begin{array}{l}3-4 \\
3-2 \\
1-4 \\
1-2\end{array}$} \\
\hline & $2=$ posterior üst & 8 & 4.88 & 5 & 3 & 7 & 1.46 & 20.44 & & & \\
\hline & $3=$ anterior alt & 6 & 1.17 & 1 & 0 & 3 & 1.17 & 6.25 & & & \\
\hline & $4=$ posterior alt & 8 & 4.75 & 5 & 2 & 7 & 1.49 & 19.94 & & & \\
\hline \multirow{4}{*}{3 duvarlı defekt } & $1=$ anterior üst & 6 & 0.83 & 1 & 0 & 1 & 0.41 & 15.92 & \multirow{4}{*}{4.36} & \multirow{4}{*}{0.225} & \\
\hline & $2=$ posterior üst & 8 & 1.13 & 1 & 0 & 3 & 0.83 & 17.69 & & & \\
\hline & $3=$ anterior alt & 6 & 0.33 & 0 & 0 & 1 & 0.52 & 9.67 & & & \\
\hline & 4=posterior alt & 8 & 0.75 & 0.5 & 0 & 2 & 0.89 & 13.88 & & & \\
\hline \multirow{4}{*}{ kombine defekt } & $1=$ anterior üst & 6 & 0.33 & 0 & 0 & 1 & 0.52 & 7.50 & \multirow{4}{*}{16.51} & \multirow{4}{*}{0.001} & \multirow{4}{*}{$\begin{array}{l}1-4 \\
1-2 \\
3-4 \\
3-2\end{array}$} \\
\hline & $2=$ posterior üst & 8 & 2.25 & 2 & 1 & 5 & 1.39 & 20.19 & & & \\
\hline & $3=$ anterior alt & 6 & 0.33 & 0 & 0 & 1 & 0.52 & 7.50 & & & \\
\hline & 4=posterior alt & 8 & 1.88 & 2 & 1 & 3 & .83 & 19.31 & & & \\
\hline
\end{tabular}




\section{TARTIŞMA}

Periodontal kemik lezyonlarının varlığının ve morfolojisinin tanısı klinik olarak büyük bir zorluk yaratmaktadır. Genel olarak kullanılan tanı metodu, klinik ataçman seviyesinin belirlenmesi ve bu bilginin radyolojik olarak var olan bilgi ile kombine edilmesidir. Kemik defektinin şeklinin tam olarak belirlenmesi ancak flep kaldırıldıktan sonra gerçekleşir. Fakat flep kaldırılmadan önce defektin şeklinin mümkün olduğu kadar belirlenmesi doğru tedavi planının yapılabilmesi bakımından önemlidir. Kemik defektinin morfolojisi ve lokasyonunun belirlenmesi amacıyla yapılan çalışmalar radyografilerin güvenilir olmadığını ortaya koymuştur ${ }^{10,22,23}$.

Periodontitis hastalarının klinik ve radyografik bulgularının incelendiği çalışmalarda yüksek preva lansta kemik defektlerinin gözlendiği , defekt görülme sıklığının yaşla birlikte arttığı ， erkeklerde daha sık oluştuğu, mezial yüzeylerde distal yüzeye göre daha yüksek oranda bulunduğu gözlenmiştir ${ }^{16,24,25}$.

Radyografta belirlenen vertikal defektler bazı yayınlara göre en fazla molar dişlerin distalinde, bir başka yayına göre maksillada molar ve santral dişlerde, mandibulada molar dişlerin mezialinde saptanmış$\operatorname{tır}^{14,16}$. Diğer bir yayında ise mezialde distale göre daha fazla vertikal defekt bulunduğu ve maksiller dişler ile mandibular dişler arasında fark olmadığı bildirilmiştir $^{26}$. Vertikal defektlerin görülme oranı $\% 60.8$ oranında bulunmuştur ${ }^{26}$. Saari'nin kurukafada yaptığı çalışmada vertikal defektlerin daha çok mandibular molarların distalinde bulunduğu görülmüştür ${ }^{27}$. Bir diğer çalışmada ise tüm aproksimal yüzeylerin \% 1.9 'unda açılı defekt görülmüştür ${ }^{28}$. Defektlerin $\% 67$ 'i yüzeyel defektlerdir.

Yaptığımız çalışmada posterior bölgede kemik defekti görülme sıklığı anterior bölgeye göre daha yüksek olarak gözlenmiştir. Defektler kendi içlerinde incelendiğinde ise alt ve üst her iki çenede de posterior bölgede görülme sıklığının daha fazla olduğu saptanmıştır. Bu bulgu daha önce yapılan çalışmalar ile uyumlu olup, anatomik faktörler ile açıklanmaktadır. Maksiller ve mandibular anterior bölgelerdeki alveolar yapının daha ince olması, bu alanlarda horizontal kemik rezorpsiyonuna sebep olmakta ve kemikiçi defektlerin daha az görülmesine yol açmaktadır. Yine yapılan çalışmalarda periodontal cerrahi sırasında yapı- lan direkt gözlem ile kemik defektlerinin anteriordan posteriora doğru artış gösterdiği saptanmıştır ${ }^{29}$. Posterior bölgenin anterior bölgeye göre oral hijyen bakımından daha fazla ihmal edilmesi de bu bölgelerde plağa bağlı yıkımın daha fazla olmasına bir başka sebep olarak düşünülebilir.

Maksillar ve mandibular bölgelerde 1,2,3, duvarlı ve kombine kemik defektleri arasında istatistiksel olarak fark görülmezken bu bulgu Wouters ve arkadaşlarının yaptığı çalışma ile uyumludur ${ }^{16}$. 3 duvarlı defektlerin üst çenede görülme sıklığı daha fazla bulunmuştur. Maksilla ve mandibula arasındaki anatomik farklılıkların buna sebep olduğu düşünülmektedir. Maksillanın mandibulaya göre daha kanselöz, trabeküler ve ince kortikal yapıda olması inflamatuar yıkıma karşı yatkınlığını açıklamaktadır . Vertikal kemik defektlerinin meydana gelmesine sebep olan nedenler uzun zamandan beri araştırılan bir konudur . Bu defektlerin inflamasyon ve travmaya karşı direncin azalması sonucu oluştuğu belirtilirken ${ }^{1}$, okluzal travma veya alveol kemik anatomisi ile ilişkilendirenler de bulunmaktadır ${ }^{30}$. Goldman ve Cohen , bu defektlerin meydana gelmesinde diş anatomisi ve pozisyonunun , açık kontak alanlarının , düzensiz diş yapılarının ve gelişimsel kök oluklarının etkili olabileceğini belirtmiş lerdir $^{11}$. Defekt oluşumunda bir diğer önemli faktör de subgingival plağın kök yüzeyinde apikale doğru düzensiz yayılımıdır ${ }^{31,32}$.

Dişler arasındaki interdental septumun genişliği ve kalınlığı , vestibül ve lingual bölgelerdeki alveol kemik kalınlığı , komşu dişlerin kökleri arasındaki yakınlık ve diş çevresinde fenestrasyon tipi defektlerin varlığı hastalığın ilerlemesinde ve defektin morfoloji sinin belirlenmesinde etkili olmaktadır ${ }^{1}$. Papapanou ve Tonetti 2000 yılında cerrahi operasyonlarda gözlenen morfolojileri göz önünde bulundurarak yaptıkları sınıflandırmada da benzer görüşü savunmuşlarıdır ${ }^{10}$.

Çalışmamızda 185 defekt içinde en çok görülen defekt tipi 2 duvarlı defekt olarak saptanmıştır. İncelenen kemik defektleri içinde \% 50.2 oranında 2 duvarlı kemik defekti olduğu hesaplanmıştır. Kemik defektleri içinde en sık gözlenen tipin 2 duvarlı defekt olduğu yapılan çalışmalar ile daha önce ortaya konulmuştur ${ }^{20}$. Çalışmamızda 2 duvarlı defekti görülme sıklığı olarak sırasıyla kombine , 1 duvarlı defekt, 3 duvarlı defekt ve 1 duvarlı defekt tipi izlemektedir.

Kemik defektlerinin tedavisinde ilk dönemlerde hasarlı dokunun (kemik duvarları) ilgili bölgeden uzak - 
laştırılması esas hedefi oluştursa da ilerleyen yıllarda sadece kemiğin şekillendirilmesi işlemi periodontal tedavideki yerini almıştır . Patolojik cep ile kemik duvarlarının elimine edilmesi için yapılan osteoplasti ve ostektomi işlemleri periodontal rezektif işlemler olarak ifade edilmektedir. Günümüzde rezektif cerrahi hala kullanılmakla birlikte kemik grefti , yönlendirilmiş doku rejenerasyonu gibi yeni yöntemlerin kullanılmaya başlaması ile popülerliğini yitirmiştir.

Periodontal rejenerasyon kapsamında koronale pozisyone fleple birlikte kök yüzeyi biyomodifikasyonu, kemik greftleri ve implantları kullanımı , organik veya sentetik membran kullanımı (yönlendirilmiş doku rejenerasyonu) gibi pek çok prosedür yer almaktadır ${ }^{33-35}$. Kök hücre ve doku mühendisligindeki son gelismeler sayesinde dental öncül hücreler, periodontitisin tedavisi , diş çürükleri ve pulpanın iyileştirilme sinde, kraniyofasial kemik ve diş dokularının rejenerasyonunda ve hatta tam olarak dişin yerine konmasında yeni bir yaklaşım olarak karşımıza çıkmaktadır ${ }^{36}$.

Periodontal hastalık sonucu kaybedilen periodontal dokuların rejenerasyonun sağlanması periodontolog için en önemli hedeftir. Kemik defektlerinin tipi ve dağılımları hakkında yapılan çalışmalar ise bizlere yapacağımız tedavilerin planlaması ve başarısı için ışık tutmaktadır.

\section{KAYNAKLAR}

1. Newman MG, Takei HH, Caranza FA. Carranza's Clinical Periiodontology. 9th Edition. Philadelphia, Saunders Company, 2002: 67.

2. Flemming TF. Periodontitis. Ann Periodontal 1999;4 :32-7.

3. Lamster IB, Lalla E. Periodontal disease and diabetes mellitus: discussion, conclusions, and recommendations. Ann Periodontol 2001; Dec;6:146-9.

4. Emrich LJ, Shlossman M, Genco RJ. Periodontal disease in non-insulin-dependent diabetes mellitus. J Periodontal 1991;Feb;62:123-31.

5. Reddy MS. Osteoporosis and periodontitis: discussion, conclusions, and recommendations. Ann Periodontol 2001; 6:214-7.

6. Page $C$, Kornman S. The pathogenesis of human periodontitis: An introduction. Periodontol 2000 1997; 14: 9-11.
7. Rylev M, Kilian M. Prevalence and distribution of principal periodontal pathogens worldwide. J Clin Periodontol 2008; 35: 346-61.

8. Garrett S. Periodontal Regeneration Around Natural Teeth. Ann Periodontol 1996; 1: 621-666.

9. Vandersall D. Periodontic in The Next Millenium. Dent Clin North Am 1998; 42: 543-60.

10. Papapanau P, Tonetti M. Diagnosis and Epidemiology of Periodontal Osseous Lesions. Periodontol 2000, 2000; 22: 8-21.

11. Goldman HM, Cohen DW. The Infrabony Pocket: Classification and Treatment. J Periodontol 1968;29:272-88.

12. Greenberg J, Laster L, Listgarten MA. Transgingival probing as a potential estimator of alveolar bone level. J Periodontol 1976;47:514-7.

13. Eickholz P, Riess T, Lenhard M, Hassfeld S, Staehle HJ. Digitalradiography of interproximal bone loss; validity of different filters. J Clin Periodontol 1999;26:294-300.

14. Goaz PW, White SC. Oral Radiology: Principles and Interpretation. 3th Edition. St . Louis:C.V. Mosby, 1987:406-20.

15. Carranza FA, Newman MG. Bone loss and patterns of bone destruction. Caranza's Clinical Periodontology. 8th Edition. Philadelphia,W.B. Saunders, 1996, page 297-313.

16. Wouters FR, Salonen LE, Hellden LB, Frithiof L. Prevalence of interproximal periodontal intrabony defects in an adult population in Sweden; A radiographic study. J Clin Periodontol 1989;16: 144-9.

17. Gilmore ND. An epidemiological investigation of vertical osseous defects in periodontal disease. Thesis, Ann Arbor, Michigan.1970.

18. Kim CK, Choi SH, Kim TS, Kaltscmitt J, Eickholz P. The infrabony defects and determinants. J Periodontal Res.2006; Dec;41:498-502.

19. Tal H. Relationship between the interproximal distance of roots and the prevalence of intrabony pockets. J Periodontol 1984;Oct;55:604-7

20. Tal $\mathrm{H}$. The prevalence and distribution of intrabony defects in dry mandibles. J Periodontol 1984; Mar;55:149-54

21. Larato DC, Infrabony defects in the dry human skull. J Periodontol 1970;Sep;41:496-8. 
22. Greenberg J, Laster L, Listgarten MA. Transgingival probing as a potential estimator of alveolar bone level. J Periodontol 1976;47:514-517.

23. Eickholz $P$, Riess T, Lenhard M, Hassfeld S, Staehle $\mathrm{HJ}$. Digital radiography of interproximal bone loss; validity of different filters. J Clin Periodontol 1999;26:294-300.

24. Pepelassi EA, Tsiklakis K, Diamanti-Kipioti A. Radiographic detection and assessment of the periodontal endosseous defects. J Clin Periodontol 2000;27:224-30.

25. Papapanou PN, Wennstrom JL, Grondahl K. Periodontal status in relation to age and tooth type. A cross-sectional radiographic study. J Clin Periodontol 1988;15:469-78.

26. Persson RE, Hollender LG, Laurell L, Persson GR. Horizontal alveolar bone loss alveolar bone loss and vertical bone defects in an adult patient population. Journal of Periodontology 1998; 69,348-56.

27. Saari JT, Hurt WC, Biggs NL. Periodontal bony defects in the dry skull. J Periodontal 1968;39:278

28. Papapanou PN, Wennström JL. The angular bony defect as indicator of further alveolar bone loss. Journal of Clinical Periodontology 1991;18,317-22.

29. Vrotsos JA, Parashis AO, Theofanatos GD, Smulow JB. Prevalence and distribution of bone defects in moderate and advanced adult periodontitis. J Clin Periodontol 1999; 26: 44-8.

30. Glickman I, Smulow JB. Effect of Excessive Occlusal Forces Upon the Pathway of Gingival Inflammation in Humans. J Periodontol 1965;36:141-7.

31. Waerhaug J. The infrabony pocket and its relationship to trauma from occlusion and subgingival plaque. J Periodontol 1979;50:355-65.

32. Waerhaug J. The angular bone defect and its relationship to trauma from occlusion and downgrowth of subgingival plaque. J Clin Periodontol 1979;6:61-82.

33. Toygar HU , Arpak N , Güzeldemir E . Farklı iki yapıda membran kullanılarak gerçeklestirilen yönlendirilmis doku rejenerasyonu tekniginin 5 yıllık klinik sonuçlarının degerlendirilmesi. A.Ü. Dis Hek. Fak. Derg. 2006; 33: 89-96.

34. Markou N, Pepelassi E, Vavouraki H. Treatment of periodontal endosseous defects with platelet-rich plasma alone or in combination with demineralized freeze-dried bone allograft: a comparative clinical trial. J Periodontol 2009 Dec;80:1911-9.

35. Reynolds MA, Aichelmann-Reidy ME, Branch-Mays GL, Gunsolley JC. The efficacy of bone replacement grafts in the treatment of periodontal osseous defects. A systematic review. Ann Periodontol 2003;Dec;8:227-65.

36. Özcan E, Özcan SSA. Periodontal rejenerasyonda kök hücrenin yeri. A.Ü.Dis Hek. Fak Derg 2010; 20: 123-30.

\section{Yazışma Adresi:}

Dr.Dt. Pelin GÖKALP

Ataköy 9.kısım A11/B

Daire:136 Ataköy

İSTANBUL

e-mail: pgokalp@gmail.com 